\title{
Catastrophic Hydraulic Failure and Tipping Points in Plants
}

\author{
Daniel Johnson ${ }^{1}$, Gabriel G Katul ${ }^{2}$, and Jean-Christophe Domec ${ }^{3}$ \\ ${ }^{1}$ University of Georgia \\ ${ }^{2}$ Duke University \\ ${ }^{3}$ Bordeaux Sciences Agro
}

December 13, 2021

\begin{abstract}
Water inside plants forms a continuous chain from water in soils to the water evaporating from leaf surfaces. Failures in this chain result in reduced transpiration and photosynthesis and these failures are caused by soil drying and/or cavitationinduced xylem embolism. Xylem embolism and plant hydraulic failure share a number of analogies to "catastrophe theory" in dynamical systems. These catastrophes are often represented in the physiological and ecological literature as tipping points or alternative stable states when control variables exogenous (e.g. soil water potential) or endogenous (e.g. leaf water potential) to the plant are allowed to slowly vary. Here, plant hydraulics viewed from the perspective of catastrophes at multiple spatial scales is considered with attention to bubble expansion (i.e. cavitation), organ-scale vulnerability to embolism, and whole-plant biomass as a proxy for transpiration and hydraulic function. The hydraulic safety-efficiency tradeoff, hydraulic segmentation and maximum plant transpiration are examined using this framework. Underlying mechanisms for hydraulic failure at very fine scales such as pit membranes, intermediate scales such as xylem network properties and at larger scales such as soil-tree hydraulic pathways are discussed. Lacunarity areas in plant hydraulics are also flagged where progress is urgently needed.
\end{abstract}

\section{Hosted file}

Catastrophic Hydraulic Failure and Tipping Points in Plants Main Doc.pdf available at https://authorea.com/users/371022/articles/549104-catastrophic-hydraulic-failure-andtipping-points-in-plants

\section{Hosted file}

Figures.pdf available at https://authorea.com/users/371022/articles/549104-catastrophichydraulic-failure-and-tipping-points-in-plants 